\title{
Commentary: Could We Address the Interplay Between CD133, Wnt/ $\beta$-Catenin, and TERT Signaling Pathways as a Potential Target for Glioblastoma Therapy?
}

\author{
Christine A. Fargeas ${ }^{1}$, Aurelio Lorico ${ }^{2}$ and Denis Corbeil ${ }^{1 *}$ \\ 1 Tissue Engineering Laboratories, Biotechnology Center (BIOTEC) and Center for Molecular and Cellular Bioengineering, Technische \\ Universität Dresden, Dresden, Germany, ${ }^{2}$ College of Medicine, Touro University Nevada, Henderson, NV, United States
}

Keywords: CD133, cilium, prominin-1, membrane vesicle, Wnt/ $\beta$-catenin, glioblastoma

\section{A Commentary on}

\section{OPEN ACCESS}

Edited by:

Shao-Chun Wang,

China Medical University, Taiwan

Reviewed by:

Gunes Ozhan,

Dokuz Eylül University, Turkey

*Correspondence:

Denis Corbeil

denis.corbeil@tu-dresden.de

Specialty section:

This article was submitted to Molecular and Cellular Oncology,

a section of the journal

Frontiers in Oncology

Received: 20 May 2021

Accepted: 26 July 2021

Published: 12 August 2021

Citation:

Fargeas CA, Lorico A and Corbeil D (2021) Commentary: Could We Address the Interplay Between CD133, Wnt/ $\beta$-Catenin, and TERT Signaling Pathways as a Potential Target for Glioblastoma Therapy?

Front. Oncol. 11:712358.

doi: 10.3389/fonc.2021.712358
Could We Address the Interplay Between CD133, Wnt/ $\beta$-Catenin, and TERT Signaling Pathways as a Potential Target for Glioblastoma Therapy?

by Behrooz AB and Syahir A (2021). Front Oncol. 11:642719. doi: 10.3389/fonc.2021.642719

We do not intend to analyze here the meaning of the title of the article "Could We Address the Interplay Between CD133, Wnt/ $\beta$-Catenin, and TERT Signaling Pathways as a Potential Target for Glioblastoma Therapy?" by Behrooz and Syahir published recently in Frontiers in Oncology [issue April 1, 2021]. Yet, it is important to mention that essential data regarding the biology of prominin-1 (prom1, a.k.a. CD133) are missing and the work of others is mistakenly described. We here provide these quotations to guide the reader to the literature pertinent to the question raised.

Targeting prominin-1-expressing cells in relation to signaling cascades for cancer therapy has indeed been the concern of many over the past decade. To fully apprehend the clinical potential of targeting strategies, it is important to provide the complete and accurate account of the biology of prominin-1. Initially identified as a marker for plasma membrane protrusions in mouse embryonic neuroepithelial cells, the primary neural stem cells (1), prominin-1 has been used to identify and purify murine stem cells from the adult subventricular zone along the lateral ventricle walls, hippocampal dentate gyrus, and the postnatal cerebellum, which has important implications for the comprehension of cerebellar development and the origins of medulloblastoma (2-5). Its human homolog (6) was identified on a subpopulation of $\mathrm{CD} 4^{+}$hematopoietic stem cells (7) and characterized from retinoblastoma cell lines (8). Human neural precursors were shown to harbor prominin-1 (9), which was later used to identify and purify brain tumor stem cells (10). Since then, prominin-1 has been considered as a prominent marker associated with tumor development in the field [see the review (11) and references therein].

An interconnection between prominin-1 and canonical Wnt pathway was initially suspected in melanoma cells several years ago (12). The downregulation of prominin-1 prevented the nuclear localization of $\beta$-catenin and reduced Wnt signaling through TCF/LEF transcription factor (13). Yet, the Wnt/ $\beta$-catenin pathway could still be activated by its physiological ligands 
as nuclear localization of $\beta$-catenin was restored upon addition of Wnt3a to prominin-1-knockdown cells (13). TCF-LEFbinding sites are present in the PROM1 gene promoter (14). Interaction of prominin-1 with histone deacetylase 6 was shown to stabilize $\beta$-catenin in a colon carcinoma cell line (15), and prominin-1 was suggested to mediate activation of the phosphoinositide 3-kinase ( $\mathrm{PI} 3 \mathrm{~K}) /$ protein kinase $\mathrm{B}(\mathrm{AKT})$ pathway in glioma stem cells by its binding to $\mathrm{p} 85$ regulatory subunit of PI3K (16). The interplay between these pathways and others in carcinogenesis was discussed in a Letter to the Editor entitled "An intriguing relationship between lipid droplets, cholesterol-binding protein CD133 and Wnt/ $\beta$-catenin signaling pathway in carcinogenesis" (17).

In the context of brain cancer, it is essential to note that many cells in the adult central (and peripheral) neural systems, other than cells with stem cell properties (i.e., self-renewal and differentiation capacities) that reside in the subventricular zone or subgranular zone of the hippocampus, express prominin-1 (18-21). Although the expression profile appears to be different in humans (21), the unrestricted expression of prominin-1 by multiple cell types including multiciliary ependymal cells and other glial cells tend to indicate that its association with stem cells properties is not absolute [reviewed in (22)]. Indeed, prominin-1 is detected within white matter tracts of postnatal and adult brain $(21,23)$, where it is expressed by a subset of cells within the oligodendrocyte lineage and is a constituent of myelin sheaths $(23,24)$. Consistently, its expression is drastically reduced in the brain of myelin-deficient mice (23), and hypomyelination and cognitive impairment were observed in mice lacking prominin-1 (24). Prominin-1 is also detected in a subgroup of astrocytes (B1 type) that are in contact with the lateral ventricle, including those that act as quiescent or activated neural stem cells in adults $(3,25)$. There, prominin-1 concentrates at the tip of the primary cilia of the quiescent stem cells and redistributes across the apical surface of the activated ones that are devoid of primary cilium. It remains to be established whether prominin-1 itself is somehow involved in the stem cell activation process therein, as recently demonstrated in mouse dental stem cells (26). Interestingly, in proneural glioblastoma-like tumor cells, prominin-1 is expressed by the endothelium that supports microvascular proliferation and accelerates tumor growth (20). On the other hand, several studies concluded that prominin-1 expressing cells were dispensable for gliomagenesis (18, 27, 28). Holmberg-Olausson and colleagues provided evidence that human prominin-1 may constitute a tumor cell-intrinsic marker independent of stem cell properties, as they observed a variability of prominin-1 expression levels in human glioblastoma, where higher prominin-1 expression correlated with shorter patient survival (21). This differential expression of prominin-1 may be reflected in the amount of prominin $-1^{+}$membrane vesicles found in the cerebrospinal fluid of glioblastoma patients (29) (see below).

The presence of distinct prominin-1 splicing variants in neural stem cells, oligodendrocytes, and astrocytes, which suggests related but distinct functions (5, 23, 30), adds complexity to the analysis of the origin of neural cancer cells notably by immunohistochemistry, as prominin-1 splice variants may differentially mark cell subpopulations in glioma. Besides, the detection of human prominin-1 can be altered by the use of certain anti-prominin-1 antibodies whose corresponding epitopes may be masked under native conditions (31). These issues have led to the generation of contradictory data and discussions and should be kept in mind when addressing prominin-1 in normal and pathological conditions such as brain cancer.

In addition to cellular components, it is important to describe that prominin- 1 is released in association with membrane vesicles into the cerebrospinal fluid (32), and their amount is elevated in glioblastoma patients (29), which could impact the surrounding cells in the cancer microenvironment and beyond. Prominin- $1^{+}$ vesicles, budding from microvilli and/or primary cilia, could be the source of signals between cells as they facilitate the exchange of active molecules (33). In cancer, some studies suggest that prominin-1 is also associated with exosomes $(13,32,34)$ as demonstrated in blood stem cells (35). It remains to be demonstrated whether these prominin $-1^{+}$membrane particles help in cell differentiation, as Behrooz and Syahir wrote. In other words, it is not completely clear whether the differentiation process is induced by the loss of prominin- $1^{+}$vesicles or whether their release is a consequence of differentiation. Data suggest that the former may occur in colon cancer $(32,34)$. In addition, it is worth mentioning that prominin- 1 has been shown to segregate symmetrically/asymmetrically during cell division in glioma stem cells in the presence or absence of growth factors, which contributes to the maintenance of the cancer stem cell pool in the tumor and its cellular heterogeneity (36). As a result, the context of signaling would differ in the different cell progeny. Importantly, targeting prominin-1 might, beyond impacting prominin-1 expressing cells, also alter prominin $-1^{+}$vesiclemediated intercellular communication within the cancer stem cell microenvironment.

The authors present prominin-1 as a surface receptor, citing their previous review in J. Drug Target [issue March 2019], and prominin-1, Wnt/ $\beta$-catenin, and TERT as three signaling cascades. Recently, a prominin-1-AKt-Wnt signaling axis in glioblastoma tumor-initiating cells was indeed described, leading to the hypothesis that prominin-1 may act as a putative surface receptor (37). Yet, to the best of our knowledge, no extracellular ligand, the binding of which would generate signal transduction, was described for prominin-1. This molecule is involved in various protein-protein and lipid-protein interactions notably those regulating the architecture and dynamics of filopodia, microvilli, and cilia $(26,38,39)$. Behrooz and Syahir wrote that "the rigorous function of CD133 maintains unidentified, but it has been proposed that it would perform as cell membrane topology organizer". However, they did not cite any reference nor developed this aspect. We therefore recommend the following review for further reading on this topic (40). Indeed, as the primary cilium is an important signaling hub during development and in mature brain, and numerous ciliaryassociated genes are dysregulated in cancer, the implication of prominin-1 in the dynamics of primary cilium might potentially account, at least partially, for its interplay with several signaling pathways found therein, including $W n t / \beta$-catenin (41). In this 
regard, it is of note that the absence of prominin-1 as an organizer of plasma membrane protrusions impairs the general configuration of ependymal cilia, and potentially their functions such as mediating the circulation of cerebrospinal fluids necessary for brain homeostasis and delivering signaling molecules (42). Thus, prominin-1 could be considered a marker for cells with high plasma membrane dynamics and turnover, including cells with high proliferative potential and self-renewal capacity. The implication of prominin-1 in signaling

\section{REFERENCES}

1. Weigmann A, Corbeil D, Hellwig A, Huttner WB. Prominin, a Novel MicrovilliSpecific Polytopic Membrane Protein of the Apical Surface of Epithelial Cells, Is Targeted to Plasmalemmal Protrusions of Non-Epithelial Cells. Proc Natl Acad Sci U S A (1997) 94:12425-30. doi: 10.1073/pnas.94.23.12425

2. Lee A, Kessler JD, Read TA, Kaiser C, Corbeil D, Huttner WB, et al. Isolation of Neural Stem Cells From the Postnatal Cerebellum. Nat Neurosci (2005) 8:723-9. doi: 10.1038/nn1473

3. Beckervordersandforth R, Tripathi P, Ninkovic J, Bayam E, Lepier A, Stempfhuber B, et al. In Vivo Fate Mapping and Expression Analysis Reveals Molecular Hallmarks of Prospectively Isolated Adult Neural Stem Cells. Cell Stem Cell (2010) 7:744-58. doi: 10.1016/j.stem.2010.11.017

4. Obermair FJ, Fiorelli R, Schroeter A, Beyeler S, Blatti C, Zoerner B, et al. A Novel Classification of Quiescent and Transit Amplifying Adult Neural Stem Cells by Surface and Metabolic Markers Permits a Defined Simultaneous Isolation. Stem Cell Res (2010) 5:131-43. doi: 10.1016/j.scr.2010.05.001

5. Walker TL, Wierick A, Sykes AM, Waldau B, Corbeil D, Carmeliet P, et al. Prominin-1 Allows Prospective Isolation of Neural Stem Cells From the Adult Murine Hippocampus. J Neurosci (2013) 33:3010-24. doi: 10.1523/ JNEUROSCI.3363-12.2013

6. Corbeil D, Röper K, Hellwig A, Tavian M, Miraglia S, Watt SM, et al. The Human AC133 Hematopoietic Stem Cell Antigen Is Also Expressed in Epithelial Cells and Targeted to Plasma Membrane Protrusions. J Biol Chem (2000) 275:5512-20. doi: 10.1074/jbc.275.8.5512

7. Yin AH, Miraglia S, Zanjani ED, Almeida-Porada G, Ogawa M, Leary AG, et al. AC133, a Novel Marker for Human Hematopoietic Stem and Progenitor Cells. Blood (1997) 90:5002-12. doi: 10.1182/blood.V90.12.5002

8. Miraglia S, Godfrey W, Yin AH, Atkins K, Warnke R, Holden JT, et al. A Novel Five-Transmembrane Hematopoietic Stem Cell Antigen: Isolation, Characterization, and Molecular Cloning. Blood (1997) 90:5013-21. doi: 10.1182/blood.V90.12.5013

9. Uchida N, Buck DW, He D, Reitsma MJ, Masek M, Phan TV, et al. Direct Isolation of Human Central Nervous System Stem Cells. Proc Natl Acad Sci U $S$ A (2000) 97:14720-5. doi: 10.1073/pnas.97.26.14720

10. Singh SK, Hawkins C, Clarke ID, Squire JA, Bayani J, Hide T, et al. Identification of Human Brain Tumour Initiating Cells. Nature (2004) 432:396-401. doi: 10.1038/nature03128

11. Grosse-Gehling P, Fargeas CA, Dittfeld C, Garbe Y, Alison MR, Corbeil D, et al. CD133 as a Biomarker for Putative Cancer Stem Cells in Solid Tumours: Limitations, Problems and Challenges. J Pathol (2013) 229:355-78. doi: $10.1002 /$ path.4086

12. Rappa G, Fodstad O, Lorico A. The Stem Cell-Associated Antigen CD133 (Prominin-1) Is a Molecular Therapeutic Target for Metastatic Melanoma. Stem Cells (2008) 26:3008-17. doi: 10.1634/stemcells.2008-0601

13. Rappa G, Mercapide J, Anzanello F, Le TT, Johlfs MG, Fiscus RR, et al. Wnt Interaction and Extracellular Release of Prominin-1/CD133 in Human Malignant Melanoma Cells. Exp Cell Res (2013) 319:810-9. doi: 10.1016/ j.yexcr.2013.01.003

14. Katoh Y, Katoh M. Comparative Genomics on PROM1 Gene Encoding Stem Cell Marker CD133. Int J Mol Med (2007) 19:967-70. doi: 10.3892/ ijmm.19.6.967

15. Mak AB, Nixon AM, Kittanakom S, Stewart JM, Chen GI, Curak J, et al. Regulation of CD133 by HDAC6 Promotes Beta-Catenin Signaling to cascades related to carcinogenesis needs to be further dissected. Nevertheless, prominin-1 remains promising, as a cell surface marker, for therapeutic development.

\section{AUTHOR CONTRIBUTIONS}

$\mathrm{CF}, \mathrm{AL}$, and $\mathrm{DC}$ designed and wrote the manuscript. All authors contributed to the article and approved the submitted version.
Suppress Cancer Cell Differentiation. Cell Rep (2012) 2:951-63 doi: 10.1016/j.celrep.2012.09.016

16. Wei Y, Jiang Y, Zou F, Liu Y, Wang S, Xu N, et al. Activation of PI3K/Akt Pathway by CD133-P85 Interaction Promotes Tumorigenic Capacity of Glioma Stem Cells. Proc Natl Acad Sci U S A (2013) 110:6829-34. doi: 10.1073/pnas.1217002110

17. Rappa G, Fargeas CA, Le TT, Corbeil D, Lorico A. Letter to the Editor: An Intriguing Relationship Between Lipid Droplets, Cholesterol-Binding Protein CD133 and Wnt/Beta-Catenin Signaling Pathway in Carcinogenesis. Stem Cells (2015) 33:1366-70. doi: 10.1002/stem.1953

18. Nishide K, Nakatani Y, Kiyonari H, Kondo T. Glioblastoma Formation From Cell Population Depleted of Prominin1-Expressing Cells. PLoS One (2009) 4: e6869. doi: 10.1371/journal.pone.0006869

19. Jászai J, Graupner S, Tanaka EM, Funk RH, Huttner WB, Brand M, et al. Spatial Distribution of Prominin-1 (CD133)-Positive Cells Within Germinative Zones of the Vertebrate Brain. PLoS One (2013) 8:e63457. doi: 10.1371/journal.pone.0063457

20. Ding BS, James D, Iyer R, Falciatori I, Hambardzumyan D, Wang S, et al. Prominin 1/CD133 Endothelium Sustains Growth of Proneural Glioma. PLoS One (2013) 8:e62150. doi: 10.1371/journal.pone.0062150

21. Holmberg Olausson K, Maire CL, Haidar S, Ling J, Learner E, Nister M, et al. Prominin-1 (CD133) Defines Both Stem and Non-Stem Cell Populations in CNS Development and Gliomas. PLoS One (2014) 9:e106694. doi: 10.1371/ journal.pone.0106694

22. Jászai J, Corbeil D, Fargeas CA. Comprehensive Overview of CD133 Biology in Neural Tissues Across Species. In: J Pruszak, editor. Neural Surface Antigens: From Basic Biology Towards Biomedical Applications. London: Elsevier (2015). p. 113-30.

23. Corbeil D, Joester A, Fargeas CA, Jászai J, Garwood J, Hellwig A, et al. Expression of Distinct Splice Variants of the Stem Cell Marker Prominin-1 (CD133) in Glial Cells. Glia (2009) 57:860-74. doi: 10.1002/glia.20812

24. Choi MH, Na JE, Yoon YR, Rhyu IJ, Ko YG, Baik JH. Hypomyelination and Cognitive Impairment in Mice Lacking CD133 (Prominin-1). Biochem Biophys Res Commun (2018) 502:291-8. doi: 10.1016/j.bbrc.2018.05.072

25. Codega P, Silva-Vargas V, Paul A, Maldonado-Soto AR, Deleo AM, Pastrana E, et al. Prospective Identification and Purification of Quiescent Adult Neural Stem Cells From Their In Vivo Niche. Neuron (2014) 82:545-59. doi: 10.1016/ j.neuron.2014.02.039

26. Singer D, Thamm K, Zhuang H, Karbanová J, Gao Y, Walker JV, et al. Prominin-1 Controls Stem Cell Activation by Orchestrating Ciliary Dynamics. EMBO J (2019) 38:pii:e99845. doi: 10.15252/embj.201899845

27. Beier D, Hau P, Proescholdt M, Lohmeier A, Wischhusen J, Oefner PJ, et al. CD133(+) and CD133(-) Glioblastoma-Derived Cancer Stem Cells Show Differential Growth Characteristics and Molecular Profiles. Cancer Res (2007) 67:4010-5. doi: 10.1158/0008-5472.CAN-06-4180

28. Wang J, Sakariassen PO, Tsinkalovsky O, Immervoll H, Boe SO, Svendsen A, et al. CD133 Negative Glioma Cells Form Tumors in Nude Rats and Give Rise to CD133 Positive Cells. Int J Cancer (2008) 122:761-8. doi: 10.1002/ijc.23130

29. Huttner HB, Janich P, Kohrmann M, Jászai J, Siebzehnrubl F, Blumcke I, et al. The Stem Cell Marker Prominin-1/CD133 on Membrane Particles in Human Cerebrospinal Fluid Offers Novel Approaches for Studying Central Nervous System Disease. Stem Cells (2008) 26:698-705. doi: 10.1634/stemcells.20070639

30. Fargeas CA, Joester A, Missol-Kolka E, Hellwig A, Huttner WB, Corbeil D. Identification of Novel Prominin-1/CD133 Splice Variants With Alternative 
C-Termini and Their Expression in Epididymis and Testis. J Cell Sci (2004) 117:4301-11. doi: $10.1242 /$ jcs. 01315

31. Bidlingmaier S, Zhu X, Liu B. The Utility and Limitations of Glycosylated Human CD133 Epitopes in Defining Cancer Stem Cells. J Mol Med (2008) 86:1025-32. doi: 10.1007/s00109-008-0357-8

32. Marzesco AM, Janich P, Wilsch-Bräuninger M, Dubreuil V, Langenfeld K, Corbeil D, et al. Release of Extracellular Membrane Particles Carrying the Stem Cell Marker Prominin-1 (CD133) From Neural Progenitors and Other Epithelial Cells. J Cell Sci (2005) 118:2849-58. doi: 10.1242/jcs.02439

33. Feliciano DM, Zhang S, Nasrallah CM, Lisgo SN, Bordey A. Embryonic Cerebrospinal Fluid Nanovesicles Carry Evolutionarily Conserved Molecules and Promote Neural Stem Cell Amplification. PLoS One (2014) 9:e88810. doi: 10.1371/journal.pone. 0088810

34. Lucchetti D, Calapa F, Palmieri V, Fanali C, Carbone F, Papa A, et al. Differentiation Affects the Release of Exosomes From Colon Cancer Cells and Their Ability to Modulate the Behavior of Recipient Cells. Am J Pathol (2017) 187:1633-47. doi: 10.1016/j.ajpath.2017.03.015

35. Bauer N, Wilsch-Bräuninger M, Karbanová J, Fonseca AV, Strauss D, Freund D, et al. Haematopoietic Stem Cell Differentiation Promotes the Release of Prominin-1/CD133-Containing Membrane Vesicles-a Role of the EndocyticExocytic Pathway. EMBO Mol Med (2011) 3:398-409. doi: 10.1002/ emmm. 201100147

36. Lathia JD, Hitomi M, Gallagher J, Gadani SP, Adkins J, Vasanji A, et al. Distribution of CD133 Reveals Glioma Stem Cells Self-Renew Through Symmetric and Asymmetric Cell Divisions. Cell Death Dis (2011) 2:e200. doi: 10.1038/cddis.2011.80

37. Manoranjan B, Chokshi C, Venugopal C, Subapanditha M, Savage N, Tatari N, et al. A CD133-AKT-Wnt Signaling Axis Drives Glioblastoma Brain TumorInitiating Cells. Oncogene (2020) 39:1590-9. doi: 10.1038/s41388-019-1086-x

38. Corbeil D, Röper K, Fargeas CA, Joester A, Huttner WB. Prominin: A Story of Cholesterol, Plasma Membrane Protrusions and Human Pathology. Traffic (2001) 2:82-91. doi: 10.1034/j.1600-0854.2001.020202.x
39. Thamm K, Šimaité D, Karbanová J, Bermúdez V, Reichert D, Morgenstern A, et al. Prominin-1 (CD133) Modulates the Architecture and Dynamics of Microvilli. Traffic (2019) 20:39-60. doi: 10.1111/tra.12618

40. Corbeil D, Marzesco AM, Wilsch-Bräuninger M, Huttner WB. The Intriguing Links Between Prominin-1 (CD133), Cholesterol-Based Membrane Microdomains, Remodeling of Apical Plasma Membrane Protrusions, Extracellular Membrane Particles, and (Neuro)Epithelial Cell Differentiation. FEBS Lett (2010) 584:1659-64. doi: 10.1016/j.febslet.2010.01.050

41. Lancaster MA, Schroth J, Gleeson JG. Subcellular Spatial Regulation of Canonical Wnt Signalling at the Primary Cilium. Nat Cell Biol (2011) 13:700-7. doi: 10.1038/ncb2259

42. Bachor TP, Karbanová J, Büttner E, Bermúdez V, Marquioni-Ramella M, Carmeliet P, et al. Early Ciliary and Prominin-1 Dysfunctions Precede Neurogenesis Impairment in a Mouse Model of Type 2 Diabetes. Neurobiol Dis (2017) 108:13-28. doi: 10.1016/j.nbd.2017.07.010

Conflict of Interest: The authors declare that the research was conducted in the absence of any commercial or financial relationships that could be construed as a potential conflict of interest.

Publisher's Note: All claims expressed in this article are solely those of the authors and do not necessarily represent those of their affiliated organizations, or those of the publisher, the editors and the reviewers. Any product that may be evaluated in this article, or claim that may be made by its manufacturer, is not guaranteed or endorsed by the publisher.

Copyright (๑) 2021 Fargeas, Lorico and Corbeil. This is an open-access article distributed under the terms of the Creative Commons Attribution License (CC BY). The use, distribution or reproduction in other forums is permitted, provided the original author(s) and the copyright owner(s) are credited and that the original publication in this journal is cited, in accordance with accepted academic practice. No use, distribution or reproduction is permitted which does not comply with these terms. 